\title{
Risk taking and risk sharing: Does responsibility matter?
}

\author{
Elena Cettolin ${ }^{1} \cdot$ Franziska Tausch $^{2}$
}

Published online: 16 July 2015

(C) The Author(s) 2015. This article is published with open access at Springerlink.com

\begin{abstract}
Risk sharing arrangements diminish individuals' vulnerability to probabilistic events that negatively affect their financial situation. This is because risk sharing implies redistribution, as lucky individuals support the unlucky ones. We hypothesize that responsibility for risky choices decreases individuals' willingness to share risk by dampening redistribution motives, and investigate this conjecture with a laboratory experiment. Responsibility is created by allowing participants to choose between two different risky lotteries before they decide how much risk they share with a randomly matched partner. Risk sharing is then compared to a treatment where risk exposure is randomly assigned. We find that average risk sharing does not depend on whether individuals can control their risk exposure. However, we observe that when individuals are responsible for their risk exposure, risk sharing decisions are systematically conditioned on the risk exposure of the sharing partner, whereas this is not the case when risk exposure is random.
\end{abstract}

Electronic supplementary material The online version of this article (doi:10.1007/s11166-015-9215-6) contains supplementary material, which is available to authorized users.

Elena Cettolin

e.cettolin@uvt.nl

Franziska Tausch

tausch@coll.mpg.de

1 Department of Economics, Tilburg University, P.O. Box 90153, 5000 LE Tilburg,

The Netherlands

2 Max Planck Institute For Research On Collective Goods, Kurt-Schumacher-Strae 10, 53113 Bonn, Germany 
Keywords Experiments · Decision making under risk · Risk sharing ·

Redistribution · Responsibility

\section{JEL Classifications D81 · C91}

\section{Introduction}

The fundamental premise for the support of safety nets, such as social security systems and private insurance, is that individuals are willing to share risk with others, thereby accepting the resulting redistribution of income. The decision to share risk may be backed by both insurance and redistribution motives. The first has a selfish nature, as it allows risk averse individuals to reduce their risk exposure. The second is driven by a preference for equality, as whenever risk is shared those who are lucky support the more unlucky individuals in society. The more risk is shared the more income inequalities are reduced ex-post. For a long time, the idea of tailoring insurance rates to risk types has been debated in public. ${ }^{1}$ For example, proposals to charge higher health insurance premiums to smokers and obese people have been advanced, with the motivation that a high proportion of health care costs can be directly attributed to patients' bad habits (see Cawley and Ruhm 2011 and Thomson Reuters 2011). In light of this evidence, we hypothesize that in the absence of responsibility attributions for risk exposure, redistribution motives are stronger and the willingness to share risk higher, as compared to when individuals can influence the risk they face. We test this conjecture using a controlled laboratory experiment, focusing on endogenous and exogenous differences in risk exposure. Our set-up allows studying how the support for risk sharing depends on individuals' risk preferences, their own risk exposure, and their sharing partner's risk exposure.

Empirical research on risk sharing has identified a number of factors that affect individuals' propensity to share risk, e.g. group size (Chaudhuri et al. 2010), group selection and commitment (Barr and Genicot 2008), risk preferences and social networks (Attanasio et al. 2012), one's own and others' exogenous risk profiles (Tausch et al. 2014) and reciprocity in repeated interactions (Charness and Genicot 2009). However, to the best of our knowledge, we are the first to investigate how risk sharing depends on whether individuals perceive themselves and others to be responsible for the extent to which they are exposed to risk. Our results help in understanding whether perceived choice responsibility is a crucial variable influencing the support of modern safety nets.

The experiment consists of two treatments. In the Exogenous Risks (EXO) treatment subjects cannot influence the extent to which they are exposed to risk, while in the Endogenous Risks (ENDO) treatment subjects can choose their risk exposure. In the first part of the ENDO (EXO) treatment subjects choose (are assigned) one of two risky lotteries. Both lottery options have the same expected value but differ in their variance. In the second part of both treatments, subjects are paired and one

\footnotetext{
${ }^{1}$ For recent articles see New York Times (2011), CNN (2011), and Washington Post. (2012).
} 
subject in each pair is randomly selected to choose a risk sharing level. Importantly, the risk sharing decision is made ex-ante, that is before the lotteries' outcomes are determined. The risk sharing level indicates the percentage amount that will be subtracted from the eventual outcomes and then equally redistributed in the pair at the end of the experiment. We implement the strategy method, which means that participants are asked to choose a risk sharing level both for the case that their partner faces the same risk exposure as themselves, and for the case that risk exposures differ. In the last part of the experiment we use a series of incentivized lottery choices to elicit participants' risk preferences.

Our main result is that when risk exposure is a choice (ENDO) average risk sharing among low risk taking individuals is higher when their partner is exposed to low risk as compared to high risk, while no such difference exists when risks are exogenously assigned (EXO). When further differentiating individuals based on their general risk preferences, we find that the result holds for risk averse individuals that choose a low risk exposure, and also for risk seeking individuals that choose a high risk exposure. Our results are important for understanding how responsibility attributions affect risk sharing in settings where risk exposure is perceived as a choice as opposed to settings where risk exposure is perceived as uncontrollable. Since in our experiment high and low risk exposure leads to the same outcome in expectation, our results can be considered a lower bound for the role of responsibility attributions. Their role may be more significant when the high risk has a lower expected value than the safer option.

The research in this paper is related to some experimental studies that investigate the support for ex-post income redistribution in contexts where individuals' outcomes are the product of risky decisions. In Cappelen et al. (2013) participants make choices between a risky lottery and a safe alternative and after observing the eventual outcomes, they are asked how much they want to redistribute to another randomly matched participant. The authors find that individuals who avoid risk do not redistribute much in favor of unlucky risk takers, while the willingness to reduce inequalities is higher between lucky and unlucky risk takers. Thral and Rademacher (2009) implement the solidarity game of Selten and Ockenfels (1998) and compare it to a treatment where individuals choose between a safe payment and a risky lottery. The authors show that individuals that choose the safe payment are less willing to reduce inequalities when matched with individuals that choose the lottery and become needy, as compared to individuals that become needy by pure chance. To summarize, it seems that risk taking is negatively perceived by individuals that avoid risk, and thus reduces their willingness to equalize earnings ex-post.

In the cited literature, redistribution decisions are made at a point when risk is resolved and individuals' outcomes are thus known. Naturally, however, decisions to endorse a given redistributive system or policy have consequences that affect future time periods, for which individuals' outcomes are yet uncertain. Our experiment allows testing whether responsibility for risky choices matters when individuals do not know how risk will eventually materialize. Importantly, this implies that individuals face uncertainty about whether risk sharing will be profitable for them or not. Furthermore, unlike in previous experiments, individuals cannot entirely eliminate their risk exposure but-like in reality-only influence the degree of risk exposure with their choices. 
Our paper is also related to recent studies showing that income inequalities are more acceptable when they can be traced back to factors within people's control. Surveys, as well as experiments, reveal that support for redistribution is higher among people that think that wealth results from unjust motives, like luck or immoral behavior, as opposed to hard work, effort and skills (Alesina and Glaeser 2004; Alesina and La Ferrara 2005; Fong 2011; Durante and Putterman 2009; Krawczyk 2010). It is not a trivial question whether responsibility attributions play a key role also in a risk sharing context, as it differs substantially from a context in which individuals decide about how to redistribute income.

Lastly, we contribute to a recent line of research that analyzes insurance choices from a behavioral perspective (for an overview see Richter et al. 2014). Friedl et al. (2014), for example, investigate how insurance demand is affected by social comparisons and in particular how it depends on whether risks are correlated or not. Social comparisons are also the main focus of Rohde and Rohde (2011) and Linde and Sonnemans (2012) who study how decision making under risk is affected by observing the payoffs or the risk exposure of others. In contrast to the cited studies, the choices in our set-up affect both the decision maker's and the partner's income.

The reminder of the paper is organized as follows. Section 2 describes the experimental design. Section 3 summarizes theoretical predictions and hypotheses. Results are presented in Section 4. In Section 5 we discuss the results and conclude.

\section{Experimental design}

We implement two treatments, EXO and ENDO, that differ with respect to whether subjects can choose the extent to which they are exposed to risk. Both treatments consist of three parts. In the following we describe each part in detail and point out the treatment differences.

\subsection{Risk exposure}

In the risk exposure part all subjects in ENDO make a choice between two lottery options, while in EXO subjects are assigned one of the two lotteries by a random draw operated by the computer. Subjects face a lottery choice (ENDO) or a lottery assignment (EXO) in four situations, that differ in the available lotteries. ${ }^{2}$ We employ more than one situation in order to test whether results are robust to different combinations of outcomes and probabilities. In each of the four situations participants are presented with two lotteries, R (high risk) and r (low risk). ${ }^{3}$ Both lotteries yield a high outcome, $H$, with probability $p$ and a low outcome, $l$, with probability $1-p$. Our

\footnotetext{
${ }^{2}$ We also implemented a fifth situation where subjects choose between a safe payment and a risky lottery. The data referring to this situation are however not informative for our research question and are thus not included in the analysis of this paper.

${ }^{3}$ In the experiment a neutral wording is used. Please refer to the Online Appendix for the instructions used in the experiment.
} 
Table 1 Situations in the risk exposure part

\begin{tabular}{lllll}
\hline situation & option & $\mathrm{p}$ & $\mathrm{H}$ & 1 \\
\hline I & $\mathrm{R}$ & 0.2 & 30 & 0 \\
& $\mathrm{r}$ & 0.5 & 12 & 0 \\
II & $\mathrm{R}$ & 0.6 & 10 & 0 \\
& $\mathrm{r}$ & 0.6 & 6.5 & 5 \\
III & $\mathrm{R}$ & 0.2 & 22 & 2 \\
& $\mathrm{r}$ & 0.2 & 10 & 5 \\
IV & $\mathrm{R}$ & 0.2 & 14 & 4 \\
& $\mathrm{r}$ & 0.5 & 8 & 4 \\
\hline
\end{tabular}

design thus ensures that individuals can share in the up and downside of others' outcomes. ${ }^{4}$ All the employed lotteries have the same expected value of $€ 6$, which makes decision situations easier to compare. ${ }^{5}$ At the same time, in each situation the variance of lottery $r$ is lower than that of lottery R: lottery $r$ second order stochastically dominates lottery $\mathrm{R}$, and it is thus preferred by risk averse individuals.

This design reflects the fact that in reality risky options may entail an upside or a downside as compared to less risky alternatives. For example, if a smoker's increased risk of getting lung cancer materializes, the rest of society finances his medical treatment via health insurance. If, however, the risk does not materialize, and cigarette consumption is taxed, smokers' high risk taking may benefit society.

Table 1 gives an overview of the lotteries employed in the different situations. In each situation, probabilities and outcomes are selected in a way that participants can easily compare the two lotteries. In particular, lottery $R$ and $r$ are always equal in one dimension, either with respect to the outcomes' probabilities or with respect to the value of the lower outcome of the lottery, $l$.

In situations I and II, the riskier option implies either a higher probability of ending up with a zero outcome or introduces the possibility of a zero outcome, as compared to the safer alternative. Situations III and IV are less extreme, in the sense that the low outcome of $\mathrm{R}$ is strictly larger than zero. We can thus test to what extent responsibility for risk exposure depends on the severity of the potential consequences of risk taking.

Situations are presented in random order to the participants. All participants are informed that only one of the situations will matter for their final earnings. The instructions explain that each situation is equally likely to be selected for payment at the end of the experiment.

\footnotetext{
${ }^{4}$ Lotteries with negative outcomes are not implemented as they carry a number of practical implementation problems, chiefly related to the impossibility of implementing real monetary losses in laboratory experiments.

${ }^{5}$ In situation II the expected value of $r$ is $€ 5.9$. This exception was made to avoid confronting subjects with lottery outcomes that have more than one decimal point.
} 


\subsection{Risk sharing}

At the beginning of the risk sharing part subjects are randomly matched in pairs and in each pair one subject is selected at random to choose a risk sharing level $s \in[0,100]$. The value of $s$ has to be chosen ex-ante and represents the percentage amount that is deducted from the lottery outcome of each subject after risk is resolved. In each risk sharing pair, the deducted amounts are added up and equally re-distributed at the end of the experiment. Higher values of $s$ imply lower levels of earnings' inequality, with $s=100$ leading to equal outcomes in a pair. The following expression defines the earnings of a subject $i$ resulting from the first two parts of the experiment, where $Y_{i}$ is the lottery outcome of $i$ and $Y_{j}$ is the lottery outcome of $i$ 's risk sharing partner, $j$. The lottery outcomes of $i$ and $j$ are uncorrelated.

$$
\Pi_{i}=\left(1-\frac{s}{100}\right) \cdot Y_{i}+\frac{\frac{s}{100} \cdot\left(Y_{i}+Y_{j}\right)}{2}
$$

We employ the strategy method to elicit risk sharing levels. That is, for each of the four situations in the risk exposure part, a subject chooses two values of $s$. One for the case that the risk sharing partner faces the same lottery and one for the case that he faces the alternative lottery. Within a treatment, this allows observation of whether individuals' risk sharing decisions are conditioned on the risk exposure of the risk sharing partner.

At the end of the experiment subjects are informed about the lottery chosen by (ENDO) or assigned to (EXO) their risk sharing partner. Further, the relevant risk sharing level is revealed to the subject who did not make decisions in the second part. Risk is then resolved, the chosen redistribution is implemented and earnings are determined. Instructions for the risk exposure and the risk sharing parts are administered together at the beginning of the experiment. Hence, in both treatments subjects know that decisions about risk sharing will have to be made after the risk exposure part.

\subsection{Elicitation of risk preferences}

This part of the experiment is designed to estimate subjects' risk preferences. We use the multiple choice list method (Harrison and Cox 2008) and elicit participants' certainty equivalents for the previously employed lotteries. For each lottery subjects see a screen on the computer that contains a description of the lottery and a list of 20 equally spaced sure amounts, ranging from the lottery's high to its low potential outcome. In each row of the list subjects have to make a choice between the lottery and the sure amount. To ensure a unique switching point subjects are not allowed to switch back and forth between the two. Certainty equivalents are then calculated as the arithmetic mean of the smallest sure amount preferred to the lottery and the consecutive sure amount in the list. 


\subsection{Experimental procedures}

The experiment was conducted in the Behavioral and Experimental Economics Laboratory (BEElab) at Maastricht University. Subjects were recruited online with the system ORSEE (Greiner 2004). For the computerized implementation we used the experimental software Z-tree (Fischbacher 2007). A typical session lasted approximately 1.5 hours and the average earnings were 18.70 Euro. In total 208 subjects participated in the experiment, 112 in the EXO and 96 in the ENDO treatment. ${ }^{6}$ In order to ensure participants' understanding of the instructions a set of control questions was administered before the actual start of the experiment. Before being paid out and released participants were asked to fill out a questionnaire that gathered information on their socio-economic characteristics.

\section{Predictions and hypotheses}

Consider a subject $i$ that is asked to choose how much risk he wants to share with subject $j$. If subject $i$ is motivated by his own material interest, he will choose a risk sharing level $s_{i}$ in order to maximize the expected utility of his earnings. ${ }^{7}$ Four states of the world $k$ need to be taken into account: both subjects in the pair win, both lose, $i$ wins and $j$ loses, $j$ wins and $i$ loses. Formally stated:

$$
\max _{s_{i}} E U_{i}=\sum_{k=1}^{4} p_{k} \cdot U\left(\Pi_{i, k}\right)
$$

where $p_{k}$ indicates the probability of the state of the world $k$ and $U(\cdot)$ is the utility of $i$ 's final earnings, $\Pi_{i, k}$, in state $k$ (see Eq. 1). The optimal risk sharing level $s_{i}^{*}$ depends on the decision maker's risk preferences, as captured by the shape of $U(\cdot)$, and on the risk exposure of both individuals in the risk sharing pair. In essence, a risk averse individual has a high incentive to share risk, as this decreases the variance of the risk he is exposed to. The lower the risk exposure of his partner, the more attractive it is to share risk. On the other hand, in our experiment risk sharing can never be optimal for risk seeking individuals when it implies a reduction in risk exposure. ${ }^{8}$ Importantly, if subjects are self-interested, we should observe no significant differences in risk sharing between ENDO and EXO when taking risk exposure and individual risk preferences into account.

Abundant empirical evidence has demonstrated that, in contrast to the classical assumption of self-interested agents, a considerable fraction of individuals are

\footnotetext{
${ }^{6} \mathrm{~A}$ computer problem in one session led all screens to freeze during the stage where subjects were presented the control questions. As the crash required skipping the complete stage we have no control over whether subjects understood the experimental design, and therefore discarded the data.

${ }^{7}$ Theoretical predictions can also be derived under the assumption that subjects' behavior under risk is best described by Cumulative Prospect Theory (Tversky and Kahneman 1992). The results are largely in line with those of expected utility theory and are available from the authors upon request.

${ }^{8}$ An elaborate discussion of the theoretical predictions can be found in Appendix A.
} 
characterized by a concern for others (see, for example, Sobel 2005 and Camerer 2003). Moreover, many individuals are willing to support some degree of redistribution in favor of the less fortunate, even at a personal cost (see Fong 2011, and Bowles and Polania-Reyes 2012).

Risk sharing in our experiment affects both the decision maker's and the partner's outcomes. In particular, the level of risk sharing determines the expected outcome differences between sharing partners: the less risk is shared, the higher the expected inequality. In case of complete risk sharing final outcomes are exactly equal. If we assume that individuals dislike both expected advantageous and disadvantageous inequalities (see Trautmann 2009, who formalized the seminal model by Fehr and Schmidt 1999, for the case of expected outcomes), full risk sharing is optimal, irrespective of individuals' risk exposure and of whether risk exposure is voluntary (ENDO) or not (EXO). This prediction can be intuitively understood when considering that, under full risk sharing, an individual's expected utility is 6 Euro, that is the EV of compounding one's own lottery with the one of the sharing partner. Instead, when less risk is shared, expected utility is equal to 6 Euro, the EV of the chosen lottery, minus the disutility generated by the sum of the expected inequalities, which is always positive. Most notably, the idea that people care about expected inequalities in outcomes implies that risk sharing in ENDO should not be significantly different from risk sharing in EXO.

One of the limits of this approach is that it cannot account for individuals' heterogeneous risk preferences, as utility is linear in payoffs. ${ }^{9}$ However, even if we assume that risk sharing choices are motivated by the desire to reduce both risk exposure and expected inequalities in outcomes, we would not await any difference in risk sharing behaviour between EXO and ENDO when controlling for individuals' risk exposure. This highlights the main limitation of using an approach that is purely outcomebased: it neglects how distributional preferences are affected by the way in which incomes are generated.

Several studies demonstrate that inequalities due to factors within individuals' control, such as effort, are perceived as largely justifiable, while more redistribution is observed when income differences are attributable to elements beyond people's influence, such as pure luck (see Alesina and Glaeser 2004, Cappelen et al. 2007, Durante and Putterman 2009 and Krawczyk 2010).

Whereas in EXO risk exposure is randomly assigned, participants in the ENDO treatment can influence their income by choosing their risk exposure. Thus, individuals' aversion to inequality may be higher in EXO as compared to ENDO. This leads us to formulate the hypothesis that, everything else equal, average risk sharing is higher in EXO than in ENDO [Hp1].

Cappelen et al. (2013) find that after risks are resolved, most individuals are not in favor of redistributing income from individuals who avoid risk to unlucky risk takers. At the same time most individuals are willing to eliminate ex post outcome differences resulting from differences in luck among risk-takers. Thral and Rademacher

\footnotetext{
${ }^{9}$ It would surely be worthwhile to model risk sharing decisions as depending on both risk and social preferences, but such a model is beyond the scope of this paper.
} 
(2009) study how much individuals that choose a safe option are willing to transfer to individuals that instead choose a risk, and end up with a low outcome. The authors compare transfers to a situation in which all participants are exposed to risk, and find that subjects are less generous towards those whose bad outcome is a result of risktaking as compared to those who could not choose their risk exposure. This evidence shows that individuals are less willing to reduce inequalities when they result from avoidable, as compared to unavoidable, risks. In short, responsibility for risk taking matters for redistribution decisions.

Building on this finding, we investigate whether responsibility for risk taking likewise affects risk sharing choices. In our set-up risk sharing is decided before lottery outcomes are known and hence, unlike the previously mentioned studies, it is exante not clear how redistribution will take place. However, risk exposure determines who is more likely to be in need, or will receive more help in case the low outcome materializes. Indeed, compared to its alternative, the riskier lottery entails either an increased likelihood of the bad state or a lower outcome in the bad state. We thus hypothesize that, compared to EXO, in ENDO low risk takers are relatively less supportive of redistribution with high risk takers than with low risk takers [Hp2]. To test this hypothesis, we analyze whether in ENDO individuals condition risk sharing decisions on their partner's risk exposure to a different extent as compared to EXO, after controlling for individuals' selfish incentives to share risk. As we apply the strategy method, we can observe risk sharing decisions both for the case where the partner's risk exposure is high and low.

\section{Results}

We start our analysis by comparing average risk sharing between treatments and proceed by investigating risk sharing within treatments. In particular, we investigate how an individual's decision to share risk depends on his risk exposure and risk preferences, and on the risk exposure of the sharing partner. Before we present the results on risk sharing, we estimate participants' risk preferences using the elicited certainty equivalents from the third part of the experiment.

\subsection{Elicited risk preferences}

For the elicitation of participants' risk preferences we assume a power utility function for money $U(x)=x^{\alpha}$ and estimate the parameter value of $\left.\alpha \in\right] 0, \infty[$ at the individual level, by minimizing the sum of squared distances (see Wakker 2008 and Wakker 2010). That is:

$$
\min _{\alpha} \sum_{n}\left[\left(p_{n} H_{n}^{\alpha}+\left(1-p_{n}\right) l_{n}^{\alpha}\right)^{\frac{1}{\alpha}}-c e_{n}\right]^{2}
$$

where the first term in brackets indicates the theoretically predicted certainty equivalent for lottery $n$, and $c e_{n}$ is the elicited certainty equivalent of lottery $n=1, . .9$. To correct for heteroscedasticity lotteries are normalized to uniform length. In the 
remainder we focus on the results regarding subjects that in the second part of the experiment are selected to choose the risk sharing levels. We find that the median participant is characterized by $\alpha=0.89$ (s.d. $\alpha=0.41$, mean $\alpha=0.93$ ). A majority of $67 \%$ of participants are risk averse.

Since options are randomly assigned in the EXO treatment, we observe no correlation between subjects' estimated risk preferences and the type of lotteries assigned to them (Spearman's rho $=-0.06, \mathrm{p}$-value $=0.67$ ). In other words, in many cases an individual is exposed to a risk that is not in line with his risk preferences. On the other hand, in ENDO the estimated coefficient of risk aversion $\alpha$ is positively correlated with the number of times an individual chooses the riskier option in the risk exposure part (Spearman's rho $=0.42$, p-value $<0.01$ ). This implies that the more an individual is risk seeking (averse) the more often he selects the riskier (less risky) lottery in the risk exposure part. Table 2 indicates, for each situation, the percentage of risk averse and risk seeking individuals that in the risk exposure part choose a lottery in line with their estimated risk preferences. From now on, we refer to those cases as 'consistent', and as 'inconsistent' otherwise.

In a majority of cases subjects choose a risk exposure in line with their estimated risk preferences, the occurrence of consistent behavior being especially high among risk averse individuals.

In the following analysis we present our results on risk sharing. In order to compare risk sharing between treatments, we need to account for the fact that in EXO individuals may be exposed to a risk that they would not have chosen voluntarily. We thus use individuals' estimated risk preferences as an indication of whether individuals' risk exposure in EXO is in line with their general risk preferences. In the ENDO treatment elicited risk preferences are a good predictor of risk exposure choices: thus, we first conduct the analysis of risk sharing behavior taking only individuals' chosen risk exposure into account. Successively, we also distinguish individuals based on whether their chosen risk exposure is in line with their estimated risk preferences.

\subsection{Risk sharing}

When averaging over all situations, we find that risk sharing is equal to $56 \%$ in EXO and lower in ENDO, with 51\%. The histograms in Fig. 3 in Appendix B display all risk sharing choices in EXO and ENDO. In order to test whether risk sharing is statistically significant between treatments [Hp1], we run an OLS regression with risk sharing as the dependent variable, controlling for the risk exposure of both sharing partners and the decision maker's estimated risk preferences. We find that the coefficient of the treatment dummy is insignificant, and thus conclude that there

Table 2 Risk preferences and risk exposure, ENDO

\begin{tabular}{lll}
\hline Situation & Choose $\mathrm{r}$ and $\alpha<1$ & Choose R and $\alpha>1$ \\
\hline I & $67 \%$ & $50 \%$ \\
II & $70 \%$ & $39 \%$ \\
III & $57 \%$ & $72 \%$ \\
IV & $60 \%$ & $67 \%$ \\
\hline
\end{tabular}


are no significant differences in risk sharing levels between the ENDO and EXO treatment. All regression results are reported in Appendix B.

Result 1 Average risk sharing is not significantly different when risk exposure is random as compared to when it is an individual choice.

In order to test our second hypothesis [Hp2], in the remainder we focus on the relation between risk sharing decisions and risk preferences. Since we employ the strategy method, we can apply a within-subject analysis. We compare individuals' risk sharing behavior when their sharing partner faces option $r$ to the case where their partner faces the riskier option $\mathrm{R}$.

We start by distinguishing individuals based on their risk exposure only and first look at those that were assigned (EXO) or chose (ENDO) the safer lottery r. Figure 1 shows average risk sharing in all situations separately for both treatments. The dark bars display average risk sharing levels in cases where both individuals $i$ and $j$ face option $r$, whereas the light bars represent average risk sharing when the sharing partner, $j$, faces option $\mathrm{R}$ instead.

Averaging over all low risk situations per individual, we find that in the EXO treatment risk sharing is on average 55\% when the partner's option is $\mathrm{r}$ and $57 \%$ if it is R. A two-tailed Wilcoxon signed-rank test, henceforth WS, shows that these risk sharing levels are not significantly different ( $\mathrm{p}$-value $=0.60)$. A WS test conducted for each situation separately confirms that when risks are exogenous, the partner's risk exposure is not related to risk sharing in a statistically significant way (WS test $\mathrm{p}$-value $\geq 0.51$ ). Results remain insignificant even when we only consider those subjects characterized by risk averse preferences, as measured by $\alpha$ (WS test pvalue $\geq 0.24$ ). This is important because it shows that results for EXO are not driven by the presence of individuals who are exposed to a risk that they would likely not have chosen by themselves.

Results are fairly different in the ENDO treatment. The average risk sharing level is $54 \%$ when the sharing partner chooses lottery $\mathrm{r}$ and only $45.5 \%$ in case the partner opts for lottery R. This difference is highly significantly different (WS test pvalue $=0.01$ ). A systematic trend in behavior in all situations can be observed. Among individuals who choose $r$, less risk is shared on average when the partner chooses

(a) EXO

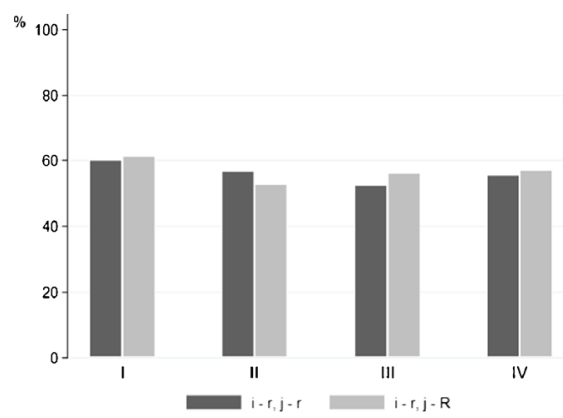

(b) ENDO

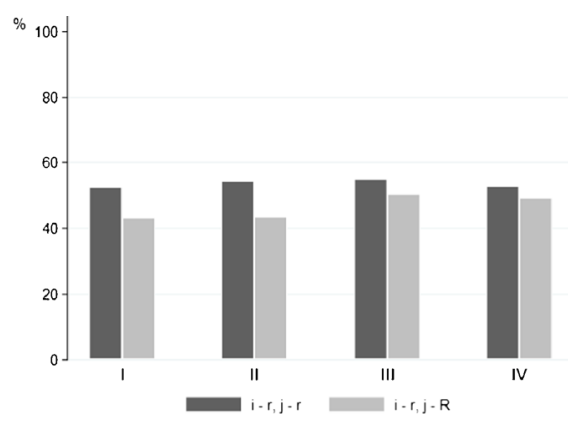

Fig. 1 Average risk sharing of subjects facing option $\mathrm{r}(\%)$ 
option $\mathrm{R}$ as compared to option $\mathrm{r}$. The difference is statistically significant in situations I and II, in which high risk taking includes the possibility of a zero outcome (WS test $\mathrm{p}$-values $\leq 0.08$ ). Results are not significant in situations III and IV (WS test $\mathrm{p}$-values $\geq 0.49$ ). We conclude that only when risk exposure is deliberate, individuals systematically condition their risk sharing behavior on their partner's risk exposure. The special role of a zero outcome for risky decisions has previously been acknowledged. Our results can be interpreted in line with Ert and Erev (2013) who find evidence for 'zero avoidance' behavior in risk taking in the domain of positive outcome lotteries. Likewise, low risk individuals here may avoid sharing the risk with individuals that are exposed to the risk of contributing nothing to the sharing pool, thereby letting the partner bear more responsibility in case the threatening zero outcome occurs.

Result 2 Individuals who choose to expose themselves to a low risk share on average less risk with a high risk taker as compared to someone who also makes a cautious choice. This difference is statistically significant when high risk taking includes the possibility of a zero outcome. When risk exposure is randomly assigned, average risk sharing does not depend on the partner's risk exposure.

We now conduct the same type of analysis for individuals that are assigned (EXO) or choose (ENDO) the riskier option R. We find that in both treatments and in all decision situations, average risk sharing does not depend on the risk exposure of the partner (WS test p-value $\geq 0.25$ ). ${ }^{10}$ Average risk sharing in EXO is $52 \%$ when the partner is assigned $\mathrm{r}$ and $57 \%$ when the partner's option is R. The according values are $50 \%$ and $52 \%$ in the ENDO treatment.

Result 3 Individuals that are exposed to a high risk do not systematically condition their risk sharing on their partner's risk exposure, regardless of whether the risk is endogenous or random.

As anticipated in the previous section, our analysis proceeds by separating the cases where subjects choose (are assigned) a risk exposure in line with their estimated risk preferences from those where this is not the case. This is especially interesting in order to understand risk sharing decisions in the ENDO treatment, as we find that subjects' behavior is systematically related to the consistency of the chosen risk exposure with the estimated risk preferences. This approach confirms that, on average, in the EXO treatment risk sharing decisions do not depend on the partner's risk exposure. Indeed, we do not observe any statistically significant differences at the aggregate level (WS test $\mathrm{p}$-value $\geq 0.37$ ) and no systematic trend at the situation specific level when we control for whether individuals face an option consistent with their estimated risk preferences. We only find a marginally significant difference (10\% level) in situation IV, where risk seeking subjects who are assigned the safer lottery share more risk with a high risk partner. In all other cases, differences are

\footnotetext{
${ }^{10}$ Figure 4 in Appendix B shows average risk sharing levels in both treatments.
} 
(a) Consistent risk averse

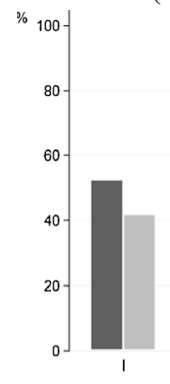

(c) Inconsistent risk averse

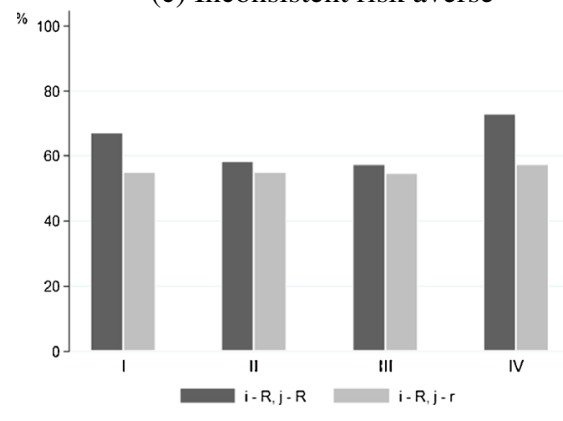

(b) Consistent risk seeking

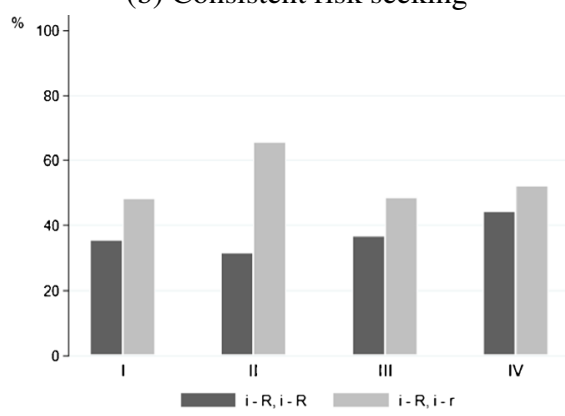

(d) Inconsistent risk seeking

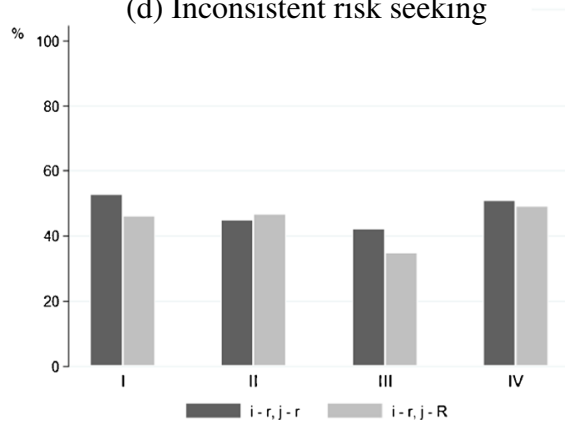

Fig. 2 Average risk sharing in ENDO taking consistency into account (\%)

statistically insignificant (WS test $\mathrm{p}$-value $\geq 0.11$ ). In the following we exclusively focus our attention on the analysis of risk sharing behavior when risks are endogenously chosen.

We first consider the cases where participants choose an option consistent with their estimated risk preferences. The importance of analyzing risk sharing behavior when choices are consistent is evident if considering that such choices are simply most frequent, as shown in Table 2. Further, many individuals display the same attitude towards risk across different domains (see Einav et al. 2012 and Dohmen et al. 2011) and hence, the following results are perhaps our most generalizable ones.

Among risk averse individuals that choose the low risk option $r$, the average risk sharing level is $58 \%$ when the sharing partner also chooses option $\mathrm{r}$, but 12 percentage points lower when the partner chooses option $\mathrm{R}(\mathrm{WS}$ test $\mathrm{p}$-value $=0.01) .{ }^{11}$ Figure $2 \mathrm{a}$ shows the average risk sharing levels in each decision situation. ${ }^{12}$

In line with the results of the previous section, we find the same pattern of behavior in situations I to IV: $i$ 's willingness to share risk with $j$ is lower when $j$ chooses the riskier lottery, R. This difference is statistically significant in situations I and II (WS

\footnotetext{
${ }^{11}$ Our unit of observation is an individual's average risk sharing level calculated over those situations where the individual chose an option in line with his estimated risk preferences.

${ }^{12} \mathrm{An}$ overview of all average risk sharing levels aggregated over the four decision situations can be seen in Table 4 in Appendix B.
} 
test $\mathrm{p}$-value $=0.08$ and 0.04 , respectively). In situations III and IV differences are insignificant (WS test $\mathrm{p}$-value $\geq 0.40$ ).

We now consider risk seeking participants that act consistently, and thus choose $\mathrm{R}$. The average sharing level is $41 \%$ in case the sharing partner also chooses option $\mathrm{R}$. In contrast, in case the sharing partner chooses option $r$, the average sharing level is $50 \%$ (WS test $\mathrm{p}$-value $=0.20$ ). Figure $2 \mathrm{~b}$ shows that when risk seeking subjects act consistently, they systematically share more risks with subjects who choose the safe option. Differences are statistically significant at the 5\% level in situation II. In the other situations, most likely because of the limited number of observations, differences are insignificant (WS test $\mathrm{p}$-value $\geq 0.36$ ). In sum, risk sharing behavior of consistent risk seeking participants displays the same tendency as in cases where risk averse individuals choose consistently: facing a high risk taker as a sharing partner reduces people's willingness to share risks.

Result 4 When risk exposure is endogenous and individuals choose their risk exposure in a consistent way, they tend to share more risk on average with a partner that made a cautious choice as compared to a risky one.

In the last part of the analysis we turn our attention to the cases where individuals in the ENDO treatment choose an option that is not in line with their estimated risk preferences. We will not try to provide an explanation of the observed inconsistencies, but rather focus on understanding risk sharing behavior in these cases. We begin by considering risk averse individuals who select option R. Risk sharing is on average 59\% when their sharing partner also chooses option R. On the other hand, when the other member chooses option $\mathrm{r}$, the average sharing level is $50 \%$. Hence, in contrast to what is observed when risk averse individuals act consistently, they share less risk if their partner chooses option $r$ (WS test $p$-value=0.15). Figure 2c shows the average sharing levels per situation. Note that in all situations $i$ shares on average less risk when $j$ chooses the safer option $r$ as compared to when he chooses R. This difference is statistically significant in situation I and IV (WS test pvalue $=0.08$ and 0.09 respectively). In the other situations differences are statistically insignificant (WS test $\mathrm{p}$-value $\geq 0.85$ ). We conclude that in case generally cautious individuals select the riskier option they prefer to share more risk with individuals who make the same risky choice.

Result 5 Risk averse individuals that decide to expose themselves to a high risk tend to share less risk with a cautious sharing partner as compared to a high risk taker.

Lastly, we note that the behavior of risk seeking individuals that choose inconsistently does not present any systematic trend. The average sharing level is $46 \%$ when the sharing partner also chose option $r$ and $44 \%$ when he chose option R (WS test $\mathrm{p}$-value $=0.75$ ). There are no significant differences within situations (WS test p-value $\geq 0.59$ ), as suggested by Fig. 2 d.

To summarize, we find a lower willingness to share risk with high risk takers whenever individuals choose a risk exposure in line with their estimated risk preferences. However, when individuals deviate from their general risk preferences, 
average risk sharing either does not depend on the partner's risk exposure or individuals share more with high risk takers. Importantly, we find that none of the described systematic differences emerges in the EXO treatment, that is when risk exposure is beyond individuals' control. Our results thus allow us to conclude that responsibility for risk exposure matters for individuals' risk sharing decisions.

\section{Discussion and conclusions}

In this study we experimentally investigate how individuals' support for risk sharing is related to whether risk exposure is deliberate or unswayable, and how it is related to individuals' own risk preferences and to the risk exposure of the sharing partner. The novelty of our experiment is that individuals make risk sharing decisions before they know their own and others' income positions. This feature is not only typical of insurance decisions, but of any context where redistribution policies that affect future periods are decided on. Our design captures the essential features of risk sharing arrangements: individuals are heterogeneous in their exposure to risk, and those exposed to a higher risk are either more likely to benefit from the redistribution inherent to risk sharing, or their benefits from redistribution in case they are unlucky are higher as compared to those of low risk takers. Our design further takes into account that high risk taking may be beneficial to the sharing group if the high risk does not materialize in a bad way. This is the case, for example, when the consumption of high risk related products, such as cigarettes or junk food, is taxed. Further, like in the field, in our setting risk exposure can only be reduced and not completely eliminated.

We find that when risks are exogenously assigned, controlling for the decision maker's risk exposure and risk preferences, average risk sharing does not systematically vary with the risk exposure of the risk sharing partner. Risk sharing behavior is fairly different, however, when individuals can choose their risk exposure. Our main finding is that individuals who avoid high risks are less willing to share risk with high risk takers as compared to low risk takers. Mitigating expected inequalities and optimizing one's risk exposure may constitute a trade-off for individuals who choose to expose themselves to a low risk. A self-interested risk averse individual would share less risk with someone who is highly exposed to risk as compared to someone whose risk exposure is low. However, unless risk is fully shared, expected inequalities are higher when the risk sharing partner is exposed to high, as compared to low, risk.

Our results suggest that the trade-off between selfish motives and equality is resolved more in favor of the former in ENDO as compared to EXO. Differently stated, the fact that cautious individuals in ENDO, but not in EXO, share relatively less risk with high risk takers as compared to low risk takers suggests that individuals are more willing to accept inequalities when high risk taking is voluntary. The fact that only in ENDO high risk takers tend to share more risk with partners that choose the safer lottery also suggests that, when risk exposure is voluntary, individuals give relatively more weight to inequality reduction with cautious partners. In other words, individuals are less willing to share their fate with someone who willingly chose to expose himself to a high risk. We conclude that responsibility attributions for risk taking systematically affect individuals' risk sharing behavior. In particular, 
choosing an avoidable high risk exposure translates into increased responsibility for one's fate, even though outcomes are not yet known when the risk sharing decision is made.

An alternative interpretation of our results is that risk sharing decisions are motivated by an altruistic act of respect towards the risk preferences of the risk sharing partner. When risk exposure is endogenous, individuals may infer their partner's risk preferences from his lottery choice. For example, a risk averse individual may judge a partner that opts for the high risk lottery as risk seeking, and thus share less risk with him. When risk exposure is instead exogenous, drawing inferences about risk preferences is not possible, and hence individuals do not condition risk sharing on their partner's risk exposure. Our data do not allow us to entirely dismiss this interpretation of the results. However, the existing literature on ex-post redistribution decisions cited in Section 3 clearly lends support to an interpretation based on the role of responsibility for risk taking.

An interesting pattern pertains to the less common situations where individuals who are generally cautious choose a high risk. The fact that these individuals tend to share more with partners that made the same risky choice suggests that when they 'dare' to take risks they can better identify with other high risk takers. This identification effect may keep individuals from lowering risk sharing and, in contrast, induce them to even share more risk with the partner they identify with. This interpretation is suggested by studies showing a positive relationship between social identification and willingness to redistribute income (see Klor and Shayo 2010, and Fowler and Kam 2007). Further investigations are however needed to test the robustness of this effect.

To conclude, our results do not only confirm that social comparisons of income matter in decision contexts characterized by risk, they also suggest that the way in which risk is perceived influences how much risk sharing decisions incorporate social concerns. It remains an open question, under which circumstances some preferences and behaviors are perceived as more exogenous, and thus less deserving of condemnation than others (Bossert and Fleurbaey 1996).

Acknowledgments Financial support by the Network for Studies on Pensions, Aging and Retirement (Netspar) is gratefully acknowledged. We thank Arno Riedl, Jan Potters, Ronald Peeters and Matthew Embrey for their helpful comments. We also thank participants to the 7th Nordic Conference on Behavioral and Experimental Economics in Bergen, the 3rd Maastricht Behavioral and Experimental Symposium, seminar attendants at LMU Munich and at University of Tilburg for their suggestions.

Open Access This article is distributed under the terms of the Creative Commons Attribution 4.0 International License (http://creativecommons.org/licenses/by/4.0/), which permits unrestricted use, distribution, and reproduction in any medium, provided you give appropriate credit to the original author(s) and the source, provide a link to the Creative Commons license, and indicate if changes were made.

\section{Appendix A: Theoretical predictions}

In order to make quantitative predictions on allocations, we assume that subjects are characterized by a CRRA utility function for money, that is $U(x)=x^{\alpha}$. A risk 
Table 3 Optimal sharing level $s^{*}$ of $i$

\begin{tabular}{llllllllll}
\hline & \multicolumn{1}{c}{ i is risk averse } & \multicolumn{1}{c}{ i is risk seeking } \\
\hline i's option & $\mathrm{r}$ & $\mathrm{r}$ & $\mathrm{R}$ & $\mathrm{R}$ & $\mathrm{R}$ & $\mathrm{R}$ & $\mathrm{r}$ & $\mathrm{r}$ \\
j's option & $\mathrm{r}$ & $\mathrm{R}$ & $\mathrm{R}$ & $\mathrm{r}$ & $\mathrm{R}$ & $\mathrm{r}$ & $\mathrm{R}$ & $\mathrm{r}$ \\
$s^{*}$ of $i$ & 100 & {$[7,48]$} & 100 & 100 & 0 & 0 & 100 & 0 \\
\hline
\end{tabular}

neutral individual is characterized by $\alpha=1$, a risk averse individual by $0<\alpha<1$ and a risk loving individual by $\alpha>1$.

Recall that in the first part of the EXO treatment each subject is randomly assigned either option $r$ or the riskier option R: hence, in a pair of subjects four combinations of lotteries are possible. Furthermore, the optimal risk sharing level $s^{*}$ depends on whether a subject is risk averse or risk seeking. ${ }^{13}$ Hence, eight possible cases need to be considered: Table 3 summarizes the predicted optimal sharing levels for all cases in situations I, III and IV.

Columns three and four of Table 3 show that for a risk averse subject $i$ full risk sharing is optimal if assigned a risky option, irrespective of the option assigned to the other subject in the pair, $j$. This is because the benefits of reducing risk exposure predominate even if $j$ faces the riskier option $\mathrm{R}$. If $i$ is assigned option $\mathrm{r}$, the optimal sharing level is $100 \%$ if $j$ was also assigned option $\mathrm{r}$. On the other hand, if $j$ is assigned option $\mathrm{R}$, the optimal sharing levels depend on the situation and are within the range of $7-48 \%$. In this case the optimal sharing level for $i$ results from a trade off between reducing risk exposure and facing $j$ 's riskier option $\mathrm{R} .{ }^{14}$ For a risk seeking subject $i$ it is only beneficial to share risk if $j$ faces a riskier option than he does. The optimal risk sharing level in that case is $100 \% .^{15}$

Optimal risk sharing levels are unchanged in the ENDO treatment. Expected Utility Theory predicts that in the risk exposure part subjects choose an option consistent with their own risk preferences, i.e. a risk averse (seeking) individual should choose option $\mathrm{r}(\mathrm{R})$. This is also true when considering that choices in the first part of the experiment can be strategically motivated. That is, subjects have no incentives to choose an option that is not in line with their own risk preferences even when they account for the existence of a successive risk sharing phase.

To summarize, for a given combination of risk preferences and risk exposure, expected utility theory predicts that risk sharing behavior is identical in the ENDO and the EXO treatment.

\footnotetext{
${ }^{13}$ When subject $i$ is risk neutral, there is no uniquely defined $s^{*}$ if the lotteries are characterized by the same expected value. In such a case $E U_{i}$ is indeed constant and independent of $s$.

${ }^{14}$ Some exceptions apply to situation II due to the small expected value difference between lotteries. Optimal risk sharing is higher than $48 \%$ for slightly risk averse individuals that face $r$ and whose partner faces R. Further, for those individuals optimal risk sharing is lower than $100 \%$ when their lottery is R and their partner's lottery is $r$.

${ }^{15}$ In situation I for $\alpha<1.17$ zero risk sharing is also a solution.
} 


\section{Appendix B: Regression results and additional graphs}

In both treatments the most common risk sharing choice is $50 \%$. Further, the frequency of full risk sharing, $100 \%$, is considerable in both treatments, with approximately $15 \%$ of the individuals choosing it.

(a) EXO

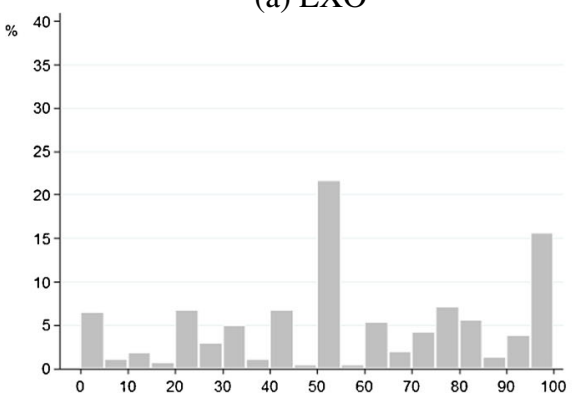

(b) ENDO

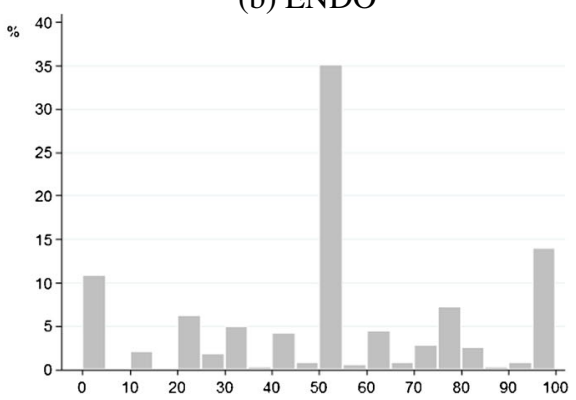

Fig. 3 Histogram of risk sharing choices (\%)

Table 4 Aggregate average risk sharing (\%)

\begin{tabular}{|c|c|c|c|c|c|}
\hline \multicolumn{2}{|c|}{ Risk exposure } & \multicolumn{2}{|l|}{ ENDO } & \multicolumn{2}{|l|}{ EXO } \\
\hline Own & Partner & consistent & inconsistent & consistent & inconsistent \\
\hline $\mathrm{r}$ & $\mathrm{r}$ & $58 \%$ & $46 \%$ & $55 \%$ & $57 \%$ \\
\hline $\mathrm{r}$ & $\mathrm{R}$ & $46 \%$ & $44 \%$ & $56 \%$ & $62 \%$ \\
\hline $\mathrm{R}$ & $\mathrm{R}$ & $41 \%$ & $59 \%$ & $55 \%$ & $58 \%$ \\
\hline $\mathrm{R}$ & $\mathrm{r}$ & $50 \%$ & $50 \%$ & $51 \%$ & $53 \%$ \\
\hline
\end{tabular}

Table 5 Risk sharing level, treatment comparison

Note: Standard errors are robust to heteroscedasticity and are clustered around subjects; the case i-r, j-r is the omitted treatment category; ENDO is a treatment dummy

\begin{tabular}{lll}
\hline Variable & Coefficient & (Std. Err.) \\
\hline ENDO & -4.753 & $(3.752)$ \\
i-r, j-R & -3.638 & $(2.331)$ \\
i-r, j-R & -1.139 & $(3.396)$ \\
i-R, j-r & -2.018 & $(2.843)$ \\
alpha & 1.758 & $(3.910)$ \\
Intercept & $55.860^{* * *}$ & $(4.402)$ \\
& & \\
$\mathrm{N}$ & & 832 \\
$\mathrm{R}^{2}$ & & 0.009 \\
$\mathrm{~F}_{(5,103)}$ & .969 \\
\hline
\end{tabular}


(a) EXO

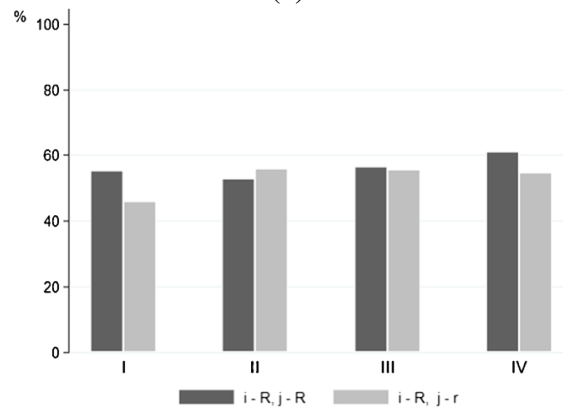

(b) ENDO

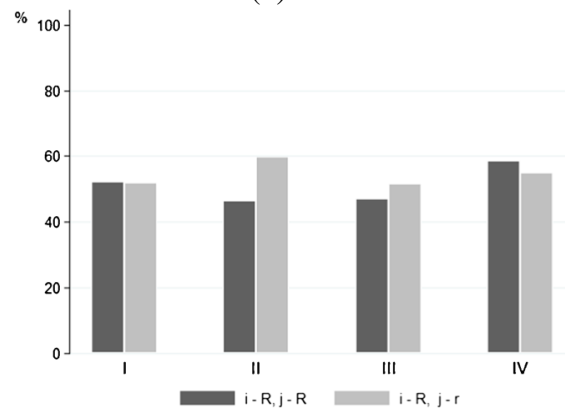

Fig. 4 Average risk sharing of subjects facing option R (\%)

\section{References}

Alesina, A., \& La Ferrara, E.L. (2005). Preferences for redistribution in the land of opportunities. Journal of Public Economics, 89, 897-931.

Alesina, A., \& Glaeser, E.L. (2004). Fighting poverty in the US and Europe: a world of difference. Oxford: Oxford University Press.

Attanasio, O., Barr, A., Cardenas, J.C., Genicot, G., \& Meghir, C. (2012). Risk pooling, risk preferences, and social networks. American Economic Journal: Applied Economics, 4(2), 134-167.

Barr, A., \& Genicot, G. (2008). Risk sharing, commitment and information: an experimental analysis. Journal of the European Economic Association, 6(6), 1151-1185.

Bossert, W., \& Fleurbaey, M. (1996). Redistribution and compensation. Social Choice and Welfare, 13(3), 342-355.

Bowles, S., \& Polania-Reyes, S. (2012). Economic incentives and social preferences: substitutes or complements? Journal of Economic Literature, 50(2), 368-425.

Camerer, C.F. (2003). Behavioral game theory: experiments in strategic interaction. Princeton: Princeton University Press.

Cappelen, A.W., Hole, A.D., Sorensen, E., \& Tungodden, B. (2007). The pluralism of fairness ideals: An experimental approach. American Economic Review, 97(3), 818-827.

Cappelen, A.W., Konow, J., Sorensen, E., \& Tungodden, B. (2013). Just luck: An experimental study of risk taking and fairness. American Economic Review, 103(4), 1398-1413.

Cawley, J., \& Ruhm, C. (2011). The economics of risky health behaviors. NBER Working Paper, 17081.

Charness, G., \& Genicot, G. (2009). Informal risk sharing in an infinite-horizon experiment. The Economic Journal, 119(537), 796-825.

Chaudhuri, A., Gangadharan, L., \& Maitra, P. (2010). An experimental analysis of group size and risk sharing. Working paper. Available online at http://users.monash.edu.au/ maitra/Risksharing_march26_ 2010.pdf.

CNN (2011). Should smokers and fat people pay more for health care? Accessed May 11. http:// caffertyfile.blogs.cnn.com/2011/10/31/should-smokers-and-fat-people-pay-more-for-health-care/.

Dohmen, T., Falk, A., Huffman, D., Sunde, U., Schupp, J., \& Wagner, G.G. (2011). Individual risk attitudes: Measurement, determinants, and behavioral consequences. Journal of the European Economic Association, 9(3), 522-550.

Durante, R., \& Putterman, L. (2009). Preferences for redistribution and perception of fairness: an experimental study. Mimeo: Brown University.

Einav, L., Finkelstein, A., Pascu, I., \& Cullen, M.R. (2012). How general are risk preferences? Choices under uncertainty in different domains. American Economic Review, 102(6), 2606-38.

Ert, E., \& Erev, I. (2013). On the descriptive value of loss aversion in decisions under risk: six clarifications. Judgment and Decision Making, 8(3), 214-235.

Fehr, E., \& Schmidt, K. (1999). A theory of fairness, competition and co-operation. Quarterly Journal of Economics, 114, 817-868. 
Fischbacher, U. (2007). Z-tree: Zurich toolbox for ready-made economic experiments. Experimental Economics, 10, 171-178.

Fong, C. (2011). Social preferences, self-interest and the demand for redistribution. Journal of Public Economics, 822, 225-246.

Fowler, J., \& Kam, D. (2007). Beyond the self: Social identity, altruism, and political participation. Journal of Politics, 69(3), 811-825.

Friedl, A., De Miranda, K.L., \& Schmidt, U. (2014). Insurance demand and social comparison: An experimental analysis. Journal of Risk and Uncertainty, 48(2), 97-109.

Greiner, B. (2004). An online recruitment system for economic experiments. In Kurt Kremer, Volker Macho (Hrsg.): Forschung und wissenschaftliches Rechnen. GWDG Bericht 63. Ges. für Wiss. Datenverarbeitung, Göttingen (pp. 79-93).

Harrison, G., \& Cox, J. (2008). Risk Aversion in Experiments. Research in Experimental Economics Series. Bingley, UK: Emerald Books.

Klor, E., \& Shayo, M. (2010). Social identity and preferences over redistribution. Journal of Public Economics, 94(3), 269-278.

Krawczyk, M. (2010). A glimpse through the veil of ignorance: Equality of opportunity and support for redistribution. Journal of Public Economics, 94, 131-141.

Linde, J., \& Sonnemans, J. (2012). Social comparison and risky choices. Journal of Risk and Uncertainty, 44(1), 45-72.

New York Times (2011). The smokers' surcharge. Accessed May 11. http://www.nytimes.com/2011/11/ 17/health/policy/smokers-penalized-with-health-insurance-premiums.html.

Richter, A., Schiller, J., \& Schlesinger, H. (2014). Behavioral insurance: Theory and experiments. Journal of Risk and Uncertainty, 48(2), 85-96.

Rohde, I.M., \& Rohde, K.I. (2011). Risk attitudes in a social context. Journal of Risk and Uncertainty, 43(3), 205-225.

Selten, R., \& Ockenfels, A. (1998). An experimental solidarity game. Journal of Economic Behavior \& Organization, 34, 517-539.

Sobel, J. (2005). Interdependent preferences and reciprocity. Journal of Economic Literature, 43(2), 392436.

Tausch, F., Potters, J., \& Riedl, A. (2014). An experimental investigation of risk sharing and adverse selection. Journal of Risk and Uncertainty, 48(2), 167-186.

Thomson Reuters (2011). Paying for unhealthy behaviors. NPR health poll. October.

Thral, R., \& Rademacher, N. (2009). Bad luck vs. self-inflicted neediness - An experimental investigation of gift giving in a solidarity game. Journal of Economic Psychology, 30, 517-526.

Trautmann, S. (2009). A tractable model of process fairness under risk. Journal of Economic Psychology, $30(5), 803-813$.

Tversky, A., \& Kahneman, D. (1992). Advances in prospect theory: Cumulative representation of uncertainty. Journal of Risk and Uncertainty, 5(4), 297-323.

Wakker, P. (2008). Explaining the characteristics of the power (CRRA) utility family. Health Economics, 17, 1329-1344.

Wakker, P. (2010). Prospect Theory for Risk and Ambiguity. Cambridge: Cambridge University Press.

Washington Post. (2012). Smokers, forced to pay more for health insurance, can get help with quitting. Accessed May 11. http://www.washingtonpost.com/national/health-science/ smokers-forced-to-pay-more-for-health-insurance-can-get-help-with-quitting/2011/12/21/ gIQAaBxlWP_story.html. 